\title{
A New Approach for Light Microscopy Studies of Stomatal Complex using Sodium Hydroxide Staining
}

\author{
Paulo Roberto Diniz Da Silva, Tatiana Silveira Moura, Denise Czarnescki Da Silva, Fernanda \\ Illamas Gallon, Ferdinando Bisogno De Castro, Valdir Marcos Stefenon* \\ Nucleus of Plant Tissue Culture, Universidade Federal do Pampa, BR290 km 423, Bairro Pirai, 97300-000, São \\ Gabriel, RS, Brazil \\ valdirstefenon@unipampa.edu.br
}

\begin{abstract}
This study aimed to develop a method for staining paradermic histological preparations for analyses of the stomatal complexes in plants. Sodium hydroxide is used in order to depolymerize polyphenols and to stain the stomatal complex, being effective in species from families that are rich in polyphenols. The proposed method performed better than the iron chloride method in 13 out of 20 plant species tested. The spectral values and the microscopic images suggest that this method is useful, fast and low-cost for histological studies of stomatal complexes in polyphenol-rich plant species.
\end{abstract}

Key words: Histochemical Analysis, Stomatal Complex, Phenolic Compounds, Histochemistry INTRODUCTION

During millions of years, plants developed several compounds which are used as chemical interface with the environment. Some of such secondary metabolites are intimately associated to defense strategies of plants, being extremely important (Heath, 2002; Matem and Kneusel, 1988). These defense compounds are basically phenols and polyphenols that help the development of structural and biochemical mechanisms, generating resistance to diseases and predators (Nicholson and Hammerschindt, 1992). Pathogenic infestations may occur through fissures in the wax layer or through natural openings in the plant such as stomata and hydathodes (Medeiros et al., 2003). Therefore, some plant families present a high amount of phenolic compounds in leaves (e.g. Conde et al., 1997; Teixeira et al., 2016), mainly around the cells of the stomatal complex, where they act as a protective agent against bacterial and fungal infections (Laloraya et al., 1986). While being quite important for the plant defense, phenols directly influence histochemical methods, sometimes making light microscopic studies of plant tissues difficult.

Histochemical staining codifies biological structures and biomolecules with specific colors, supporting microscopic observation (Horobin, 2001). This is one of the principal approaches employed in plant sciences, from anatomical to genetic modification studies. Studies on plant anatomy employ histochemical methods based on different staining compounds, depending on the plant structure to be observed. These methods are based on chromatic reactions used to recognize the chemical nature of membranes and cellular content (Costa and Cunha, 2000). The most commonly employed staining compounds for staining phenolic compounds in plant cells are the tetrazolium, the mercaptite formation, and the iron chloride (Dashek, 2000). Colorimetric methods based on the use of iron chloride as staining compound are largely used in histochemical analysis of leaf tissues. However, for some plant species that produce high content of phenolic compounds, this approach may generate only moderately defined coloration of stomatal complex.

In this study, we present a method for staining stomatal complexes based on the oxidation of phenolic compounds with sodium hydroxide. The protocol was tested in 20 plant species and the iron chloride method (Johansen, 1940) was used as comparative approach in the analysis of epidermal histological preparations of the stomatal complex. 


\section{MATERIAL AND METHODS}

\section{Plant Material and Sample Preparation}

The sodium hydroxide protocol was tested in 20 plants belonging to 10 botanical families (two plants from each family): Asteraceae [Baccharis dracunculifolia D.C. and Baccharis crispa D.C.]; Cyperaceae [Cyperus distans L.f. and Cyperus rotundus L.]; Euphorbiaceae [Euphorbia millii Des Moul and Ricinus communis L.]; Lamiaceae [Hyptis brevipes and Ocimum basilicum]; Malvaceae [Malvastrum coromandelianum (L.) Garke and Triumfetta semitriloba Jacq.]; Myrtaceae [Eucalyptus grandis Hill (ex Maiden) and Eugenia uniflora L.]; Poaceae [Andropogam bicornis L. and Saccharum angusttifolius Nees]; Portulacaceae [Portulaca striata Poelln and Talinum triangulare (Jacq.) Willd]; Rhamnaceae [Hovenia dulcis Thunberg and Scutia buxifolia Reissek] and Rosaceae [Fragaria ananassa L. and Rubus occidentalis L.].

Ten basal leaves were collected from adult individuals of each species during the daylight at the summer season, totalizing 10 preparations for each species. Voucher specimens were deposited in the Herbarium Bruno Edgar Irgang (HBEI) of the Universidade Federal do Pampa, Campus São Gabriel, Brazil.

Samples of about $1.0 \mathrm{~cm} 2$ of each leaf were individually treated into test tubes with $10 \mathrm{~mL}$ of $50 \%$ nitric acid solution and heated for 1 minute to unleash the epidermis. After cooling, tubes were maintained for 5 seconds in ultrasonic bath. The epidermises were transferred into Petri plates with distillated water, extended and transferred to microscope slide. For each species, five samples were prepared using the sodium hydroxide method and five were prepared using the iron chloride method.

\section{Staining Procedures}

Sodium hydroxide staining consisted in dropping $10 \mu \mathrm{L}$ of $10 \%$ aqueous sodium hydroxide solution over the sample stretched on a microscope slide. For species from families Cyperaceae and Poaceae, in which epidermis presents subereous and silicified cells, post-staining was employed, dropping $10 \mu \mathrm{L}$ of safranin 0 solution $(1 \%$ aqueous solution) after the sodium hydroxide staining.

The iron staining protocol was performed according to Johansen (1940), by dropping $10 \mu \mathrm{L}$ of ferric chloride ( $10 \%$ aqueous solution). Microscope slide of all samples were mounted in $100 \mu \mathrm{L}$ of gelatin-glycerin at $40^{\circ} \mathrm{C}$ and maintained at room temperature for 24 hours to dry.

\section{Visualization and Image Capture}

Samples were visualized under a light microscope Imager A2 (Carl Zeiss, Germany) and photographed with an Axiocam ERc5s color camera (Carl Zeiss, Germany). Images were captured in tiff format, using the software Axiovision SE64 Rel.4.9.1 (Carl Zeiss, Germany).

\section{Color Spectrum Analysis}

The color spectrum of the images was compared between methods as a measure of the contrast, in order to evaluate the significance of the visual difference of the pictures. For each plant species, images of 30 stomata for each staining method were evaluated. Eleven points were selected in each stomata (two in the subsidiary cells, six in the guard cells and three in the stomatal opening) and the software Image J was used to analyze the spectrum of red, green and blue in all points, with values ranging from 0 (darker color) to 255 (lighter color). For each species, nine spectral means were evaluated [three colors (red, green and blue) for three stomatal structures (guard cells, subsidiary cells and stomatal opening)]. Means of each stomatal structure were obtained as the average of all measured points.

Data of the color spectra were compared across methods using the t-test, variance analysis, variation coefficient and degree of association for methods per species using the software Statistic 7.0 and RStudio. Means were compared through the Tukey's test $(\alpha=5 \%)$. 


\section{RESULTS AND DisCUSSION}

In comparison to the iron chloride method, the sodium hydroxide protocol generated better color contrast of the histological preparations for 13 out of the 20 studied species. Such better contrast was observed for Baccharis trimera (Figure 1E), Ricinus communis (Figure 1G), Eucalyptus grandis (Figure 1I), Eugenia uniflora (Figure 1M), Portulaca striata (Figure 1K), Talinum triangulare (Figure 10), Malvastrum coromandelianum (Figure 2A), Ocimum basillicum (Figure 2G) and Hovenia dulcis (Figure 2I). Colors from light yellow to light brown prevailed in the guard and subsidiary cells of these species. The stomatal opening presented dark coloration in $R$. communis, E. grandis, E. uniflora and O. basilicum. In H. dulcis, the guard cells revealed a bluish color and the stomatal opening presented yellow color.

The histological preparations for Baccharis dracunculifolia (Figure 1B), Euphorbia milli (Figure 1D), Triumfetta semitriloba (Figure 2F), Hyptis arvensis (Figure 2D), Ocimum basillicum (Figure 2H), Scutia buxifolia (Figure 2N), Fragaria vesca (Figure 2L) and Rubus occidentalis (Figure 2P) revealed better color contrast for the iron chloride method, presenting yellowish tonalities, with main coloration of the cell walls and light staining of the cellular content.

For Cyperaceae and Poaceae, the treatments with sodium hydroxide together with safranin revealed better results for all evaluated species: Andropogon bicornisi (Figure 3B), Erianthus angustifolius (Figure 3E), Cyperus distans (Figure 3H) and Cyperus rotundus (Figure 3K). However, for A. bicornis, the resolution of the pictures is about the same for this treatment and the iron chloride protocol (Figures 3B and 3C), presenting significant difference of the color spectra between treatments in only two out of nine means (Table 1).

Stomata are cellular structures with important physiological function in the leaf, but are also an entrance doors for pathogens. Therefore, different protection mechanisms evolved in plants for combating such organisms, as the production of phenolic compounds that inhibit the growth of pathogens (Lattanzio et al., 2006). Alkaline treatments were found to be effective in releasing bound phenolics in phenolic extractions (Dai and Mumper 2010), through the depolymerization of polyphenols into their monomeric and dimeric fractions (White et al., 2010). This propriety was employed to stain the stomatal complex in our procedure, being quite effective in species from families that are rich in polyphenols. On the other hand, species from families Poaceae and Cyperaceae, with low content of tannins presented weak staining of the stomatal complex. However, the use of sodium hydroxide plus safranin allowed a better visualization of the stomatal complex of Poaceae (Figures 3B and 3E).

Among treatments, statistically significant difference in spectral data was observed for 140 out of 180 tests (20 species, three colors, three stomatal structures; Table 1). Baccharis dracuncufolia, E. grandis, E. uniflora, $H$. dulcis and F. ananassa presented statistically significant difference for all nine means. For C. rotundus, $M$. coromandelia, T. semitriloba and T. triangulare, only one of the means showed non-significant difference, while B. crispa, E. millii, O. basillicum, P. striata and R. occidentalis showed two means with non-significant different between methods. Erianthus angustifolius, S. buxifolia, C. distans, $R$. communis and H. arvensis presented six means with significant difference between methods, while A. bicornis showed only two means with significant difference (Table 1).

The present work introduces a histochemical procedure for light microscopic studies of epidermal preparations. The sodium hydroxide method is a fast and low-cost approach for histological studies of stomatal complexes in plant species rich in polyphenols, such as Myrtaceae, as closely shown for Eugenia uniflora using 1000x magnification (Figures 4A and 4B). However, statements with regard to the applicability of a new reagent should always be made with care since the complex structural differences among plants will always prevent any one reagent or method from being of universal application (Johansen, 1940). Thus, the use of this procedure has to be tested for others species, broadening the extent of techniques available for researchers interested in plant histology. In addition, the nontoxic chemicals are beneficial for teaching purposes. 


\section{American Research Journal of Bio Sciences(ARJB)}

Table1. Spectral analysis of epidermal coloration. Means and standard deviation of red, green and blue spectra in subsidiary cells (six points measured), guard cells (three points measured) and stomatal opening (two points measured). Shaded cells represent means that statistically differ between methods $(p<0.05)$.

\begin{tabular}{|c|c|c|c|c|c|c|c|c|c|c|c|}
\hline & Family/ & Method & & bsidiary c & ells & & Guard & & Stor & atal open & ings \\
\hline & & & Red & Green & Blue & Red & Green & Blue & Red & Green & Blue \\
\hline & $\begin{array}{c}\text { Baccharis } \\
\text { dracuncufolia }\end{array}$ & $\mathrm{NaOH}$ & $\begin{array}{l}149.12 \\
(14.05) \\
\end{array}$ & $\begin{array}{l}150.24 \\
(13.84) \\
\end{array}$ & $\begin{array}{l}134.83 \\
(15.96) \\
\end{array}$ & $\begin{array}{l}147.12 \\
(16.01)\end{array}$ & $\begin{array}{l}142.29 \\
(15.28) \\
\end{array}$ & $\begin{array}{c}88.33 \\
(16.95) \\
\end{array}$ & $\begin{array}{l}148.51 \\
(31.81) \\
\end{array}$ & $\begin{array}{l}135.93 \\
(30.37) \\
\end{array}$ & $\begin{array}{c}66.35 \\
(31.74) \\
\end{array}$ \\
\hline 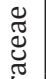 & & $\mathrm{FeCl}_{3}$ & $\begin{array}{l}201.10 \\
(24.42) \\
\end{array}$ & $\begin{array}{l}197.23 \\
(22.79) \\
\end{array}$ & $\begin{array}{l}190.10 \\
(25.23) \\
\end{array}$ & $\begin{array}{l}192.76 \\
(39.00) \\
\end{array}$ & $\begin{array}{l}197.29 \\
(26.72) \\
\end{array}$ & \begin{tabular}{|l|}
190.96 \\
$(32.72)$ \\
\end{tabular} & $\begin{array}{l}185.80 \\
(42.49) \\
\end{array}$ & $\begin{array}{l}192.01 \\
(31.40) \\
\end{array}$ & $\begin{array}{l}181.09 \\
(44.76) \\
\end{array}$ \\
\hline 离 & Baccharis trimera & $\mathrm{NaOH}$ & $\begin{array}{l}147.42 \\
(39.74) \\
\end{array}$ & $\begin{array}{l}163.75 \\
(44.82) \\
\end{array}$ & $\begin{array}{l}183.17 \\
(44.35) \\
\end{array}$ & $\begin{array}{l}138.91 \\
(45.36) \\
\end{array}$ & $\begin{array}{c}152.32 \\
(41.577) \\
\end{array}$ & \begin{tabular}{|l|}
163.91 \\
$(40.82)$ \\
\end{tabular} & $\begin{array}{l}164.10 \\
(58.92) \\
\end{array}$ & $\begin{array}{l}170.92 \\
(52.08)\end{array}$ & $\begin{array}{l}177.40 \\
(49.44) \\
\end{array}$ \\
\hline & & $\mathrm{FeCl}_{3}$ & $\begin{array}{l}210.65 \\
(24.65)\end{array}$ & $\begin{array}{l}201.82 \\
(22.23)\end{array}$ & $\begin{array}{l}179.90 \\
(27.05)\end{array}$ & $\begin{array}{l}209.56 \\
(25.57)\end{array}$ & $\begin{array}{l}201.03 \\
(20.33)\end{array}$ & $\begin{array}{l}176.91 \\
(32.03)\end{array}$ & $\begin{array}{l}199.06 \\
(38.05)\end{array}$ & $\begin{array}{l}192.70 \\
(28.98)\end{array}$ & $\begin{array}{l}168.37 \\
(35.42)\end{array}$ \\
\hline & Cyperus distans & $\mathrm{NaOH}$ & $\begin{array}{l}135.95 \\
(25.10)\end{array}$ & $\begin{array}{l}138.40 \\
(18.82)\end{array}$ & $\begin{array}{l}135.32 \\
(22.52)\end{array}$ & $\begin{array}{l}139.42 \\
(26.01)\end{array}$ & $\begin{array}{l}141.84 \\
(22.85)\end{array}$ & $\begin{array}{l}137.92 \\
(26.54)\end{array}$ & $\begin{array}{l}136.56 \\
(23.04)\end{array}$ & $\begin{array}{l}136.66 \\
(20.92)\end{array}$ & $\begin{array}{l}132.70 \\
(25.80)\end{array}$ \\
\hline & & $\mathrm{FeCl}_{3}$ & $\begin{array}{l}113.22 \\
(39.36)\end{array}$ & $\begin{array}{l}155.80 \\
(32.45)\end{array}$ & $\begin{array}{l}149.00 \\
(35.36)\end{array}$ & $\begin{array}{l}118.18 \\
(41.06)\end{array}$ & $\begin{array}{l}158.02 \\
(36.75)\end{array}$ & $\begin{array}{l}145.56 \\
(38.57)\end{array}$ & $\begin{array}{l}109.56 \\
(35.53)\end{array}$ & $\begin{array}{l}158.01 \\
(35.32)\end{array}$ & $\begin{array}{l}143.52 \\
(35.52)\end{array}$ \\
\hline 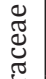 & & $\begin{array}{l}\mathrm{NaOH}+ \\
\text { Safranin }\end{array}$ & $\begin{array}{c}185.58 \\
(34.145 \\
\end{array}$ & $\begin{array}{l}191.61 \\
(36.08) \\
\end{array}$ & $\begin{array}{l}191.81 \\
(35.00) \\
\end{array}$ & $\begin{array}{l}180.02 \\
(43.36)\end{array}$ & $\begin{array}{l}177.46 \\
(40.24) \\
\end{array}$ & $\begin{array}{l}174.67 \\
(46.39) \\
\end{array}$ & $\begin{array}{l}172.34 \\
(35.53) \\
\end{array}$ & $\begin{array}{l}169.70 \\
(41.96) \\
\end{array}$ & $\begin{array}{l}164.53 \\
(38.21) \\
\end{array}$ \\
\hline 岕 & Cyperus rotundus & $\mathrm{NaOH}$ & $\begin{array}{l}114.92 \\
(38.59) \\
\end{array}$ & $\begin{array}{l}156.45 \\
(32.93)\end{array}$ & $\begin{array}{l}153.37 \\
(34.51) \\
\end{array}$ & $\begin{array}{l}120.20 \\
(41.18)\end{array}$ & $\begin{array}{l}161.88 \\
(33.29) \\
\end{array}$ & $\begin{array}{l}153.06 \\
(31.86) \\
\end{array}$ & $\begin{array}{l}100.44 \\
(26.49)\end{array}$ & $\begin{array}{l}159.00 \\
(36.32)\end{array}$ & $\begin{array}{l}144.93 \\
(38.50) \\
\end{array}$ \\
\hline & & $\mathrm{FeCl}_{3}$ & $\begin{array}{l}137.97 \\
(15.71)\end{array}$ & $\begin{array}{l}136.87 \\
(19.28)\end{array}$ & $\begin{array}{l}129.53 \\
(17.12) \\
\end{array}$ & $\begin{array}{l}130.76 \\
(18.62)\end{array}$ & $\begin{array}{l}128.00 \\
(16.99)\end{array}$ & $\begin{array}{l}121.44 \\
(20.03)\end{array}$ & $\begin{array}{l}124.30 \\
(25.89)\end{array}$ & $\begin{array}{l}127.85 \\
(15.32)\end{array}$ & $\begin{array}{l}120.33 \\
(19.02)\end{array}$ \\
\hline & & $\begin{array}{l}\mathrm{NaOH}+ \\
\text { Safranin }\end{array}$ & $\begin{array}{l}194.47 \\
(26.76)\end{array}$ & $\begin{array}{l}192.78 \\
(27.01)\end{array}$ & $\begin{array}{l}204.95 \\
(25.79)\end{array}$ & $\begin{array}{l}195.94 \\
(35.87)\end{array}$ & $\begin{array}{l}189.11 \\
(35.74)\end{array}$ & $\begin{array}{l}199.58 \\
(35.48)\end{array}$ & $\begin{array}{l}163.83 \\
(40.33)\end{array}$ & $\begin{array}{l}149.88 \\
(23.07)\end{array}$ & $\begin{array}{l}168.91 \\
(35.06)\end{array}$ \\
\hline & Euphorbia millii & $\mathrm{NaOH}$ & $\begin{array}{l}132.93 \\
(30.88)\end{array}$ & $\begin{array}{c}137.52 \\
(30.95)\end{array}$ & $\begin{array}{c}154.05 \\
(40.53)\end{array}$ & $\begin{array}{c}138.17 \\
(32.95)\end{array}$ & $\begin{array}{c}140.27 \\
(33.25)\end{array}$ & $\begin{array}{l}156.37 \\
(40.73)\end{array}$ & $\begin{array}{c}138.27 \\
(38.35)\end{array}$ & $\begin{array}{c}146.61 \\
(41.74)\end{array}$ & $\begin{array}{c}158.39 \\
(45.81)\end{array}$ \\
\hline 离 & & $\mathrm{FeCl}_{3}$ & $\begin{array}{l}168.63 \\
(20.99) \\
\end{array}$ & $\begin{array}{c}164.88 \\
(18.24)\end{array}$ & $\begin{array}{c}155.37 \\
(28.92) \\
\end{array}$ & $\begin{array}{c}172.68 \\
(16.08) \\
\end{array}$ & \begin{tabular}{|c|}
171.20 \\
$(15.98)$
\end{tabular} & $\begin{array}{l}169.04 \\
(22.01) \\
\end{array}$ & $\begin{array}{c}161.33 \\
(17.60) \\
\end{array}$ & $\begin{array}{c}160.23 \\
(20.71) \\
\end{array}$ & $\begin{array}{c}156.34 \\
(29.06) \\
\end{array}$ \\
\hline $\begin{array}{l}\frac{\tilde{L}}{0} \\
\frac{2}{2} \\
\frac{2}{z}\end{array}$ & Ricinus communis & $\mathrm{NaOH}$ & $\begin{array}{l}193.57 \\
(21.40) \\
\end{array}$ & $\begin{array}{l}204.93 \\
(20.20) \\
\end{array}$ & $\begin{array}{l}211.02 \\
(20.77) \\
\end{array}$ & $\begin{array}{l}192.34 \\
(48.23)\end{array}$ & $\begin{array}{l}207.61 \\
(40.28) \\
\end{array}$ & \begin{tabular}{|l|}
192.78 \\
$(45.47)$ \\
\end{tabular} & $\begin{array}{l}157.54 \\
(77.94) \\
\end{array}$ & $\begin{array}{l}174.12 \\
(74.42) \\
\end{array}$ & $\begin{array}{r}148.29 \\
(79.22) \\
\end{array}$ \\
\hline & & $\mathrm{FeCl}_{3}$ & $\begin{array}{l}178.03 \\
(24.19)\end{array}$ & $\begin{array}{l}199.03 \\
(22.91)\end{array}$ & $\begin{array}{l}143.23 \\
(24.71)\end{array}$ & $\begin{array}{l}171.40 \\
(29.59)\end{array}$ & $\begin{array}{l}194.09 \\
(25.05)\end{array}$ & $\begin{array}{l}139.71 \\
(26.13)\end{array}$ & $\begin{array}{l}168.69 \\
(41.74)\end{array}$ & $\begin{array}{l}193.79 \\
(34.98)\end{array}$ & $\begin{array}{l}138.84 \\
(30.93)\end{array}$ \\
\hline & Hyptis arvensis & $\mathrm{NaOH}$ & $\begin{array}{l}177.50 \\
(13.37)\end{array}$ & $\begin{array}{l}181.48 \\
(12.17)\end{array}$ & $\begin{array}{l}183.83 \\
(17.50)\end{array}$ & $\begin{array}{l}181.11 \\
(17.38)\end{array}$ & $\begin{array}{l}189.54 \\
(16.13)\end{array}$ & $\begin{array}{l}191.53 \\
(21.19)\end{array}$ & $\begin{array}{l}141.87 \\
(35.82)\end{array}$ & $\begin{array}{l}150.26 \\
(37.58)\end{array}$ & $\begin{array}{l}151.04 \\
(41.29)\end{array}$ \\
\hline 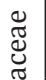 & & $\mathrm{FeCl}_{3}$ & $\begin{array}{l}189.55 \\
(25.77) \\
\end{array}$ & $\begin{array}{l}205.85 \\
(23.47) \\
\end{array}$ & $\begin{array}{l}183.73 \\
(29.05) \\
\end{array}$ & $\begin{array}{l}178.92 \\
(30.28) \\
\end{array}$ & $\begin{array}{l}196.16 \\
(25.40) \\
\end{array}$ & \begin{tabular}{|l|}
154.37 \\
$(23.51)$ \\
\end{tabular} & $\begin{array}{l}173.13 \\
(34.00) \\
\end{array}$ & $\begin{array}{l}192.42 \\
(29.39) \\
\end{array}$ & $\begin{array}{l}154.22 \\
(29.85) \\
\end{array}$ \\
\hline "ేี్ & Ocimum basillicum & $\mathrm{NaOH}$ & $\begin{array}{l}175.35 \\
(15.72)\end{array}$ & $\begin{array}{l}177.22 \\
(19.96)\end{array}$ & $\begin{array}{l}182.82 \\
(19.24)\end{array}$ & $\begin{array}{l}191.19 \\
(24.12)\end{array}$ & $\begin{array}{l}194.52 \\
(25.33)\end{array}$ & $\begin{array}{l}195.53 \\
(24.05) \\
\end{array}$ & $\begin{array}{l}152.39 \\
(45.42)\end{array}$ & $\begin{array}{l}153.94 \\
(47.48)\end{array}$ & $\begin{array}{l}153.37 \\
(48.85)\end{array}$ \\
\hline & & $\mathrm{FeCl}_{3}$ & $\begin{array}{l}198.24 \\
(32.05) \\
\end{array}$ & $\begin{array}{l}214.34 \\
(32.82) \\
\end{array}$ & $\begin{array}{l}188.29 \\
(37.40)\end{array}$ & $\begin{array}{l}192.47 \\
(29.71)\end{array}$ & $\begin{array}{l}211.05 \\
(29.70) \\
\end{array}$ & $\begin{array}{l}173.16 \\
(31.15) \\
\end{array}$ & $\begin{array}{l}191.18 \\
(41.60)\end{array}$ & $\begin{array}{l}208.47 \\
(37.21) \\
\end{array}$ & $\begin{array}{l}175.59 \\
(35.51) \\
\end{array}$ \\
\hline & $\begin{array}{c}\text { Malvastrum } \\
\text { coromandelianum }\end{array}$ & $\mathrm{NaOH}$ & $\begin{array}{l}196.05 \\
(21.72) \\
\end{array}$ & $\begin{array}{l}199.78 \\
(24.56)\end{array}$ & $\begin{array}{l}205.50 \\
(29.17)\end{array}$ & $\begin{array}{l}194.45 \\
(22.23)\end{array}$ & $\begin{array}{l}198.33 \\
(26.44)\end{array}$ & $\begin{array}{l}205.03 \\
(28.15) \\
\end{array}$ & $\begin{array}{l}190.66 \\
(27.56)\end{array}$ & $\begin{array}{l}197.53 \\
(29.23)\end{array}$ & $\begin{array}{l}202.60 \\
(31.57)\end{array}$ \\
\hline 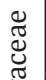 & & $\mathrm{FeCl}_{3}$ & $\begin{array}{l}184.48 \\
(25.35) \\
\end{array}$ & $\begin{array}{l}183.03 \\
(24.03) \\
\end{array}$ & $\begin{array}{l}175.48 \\
(28.03) \\
\end{array}$ & $\begin{array}{l}193.16 \\
(28.02) \\
\end{array}$ & $\begin{array}{l}188.68 \\
(26.98) \\
\end{array}$ & \begin{tabular}{|l|}
180.68 \\
$(37.36)$ \\
\end{tabular} & $\begin{array}{l}172.42 \\
(40.42) \\
\end{array}$ & $\begin{array}{l}178.04 \\
(35.44) \\
\end{array}$ & $\begin{array}{l}164.03 \\
(38.92) \\
\end{array}$ \\
\hline$\sum^{\frac{3}{\pi}}$ & $\begin{array}{l}\text { Triumfetta } \\
\text { semitriloba }\end{array}$ & $\mathrm{NaOH}$ & $\begin{array}{l}195.52 \\
(24.43) \\
\end{array}$ & $\begin{array}{l}202.95 \\
(23.71) \\
\end{array}$ & $\begin{array}{l}198.80 \\
(23.23)\end{array}$ & $\begin{array}{l}197.01 \\
(26.08)\end{array}$ & $\begin{array}{l}199.38 \\
(24.61)\end{array}$ & $\begin{array}{l}189.83 \\
(27.97)\end{array}$ & $\begin{array}{l}188.66 \\
(30.74)\end{array}$ & $\begin{array}{l}192.88 \\
(31.22)\end{array}$ & $\begin{array}{l}183.40 \\
(34.15)\end{array}$ \\
\hline & & $\mathrm{FeCl}_{3}$ & $\begin{array}{l}184.48 \\
(25.97)\end{array}$ & $\begin{array}{l}181.32 \\
(27.33)\end{array}$ & $\begin{array}{l}173.43 \\
(35.18)\end{array}$ & $\begin{array}{l}193.14 \\
(24.44)\end{array}$ & $\begin{array}{l}188.47 \\
(22.63)\end{array}$ & $\begin{array}{l}176.04 \\
(32.10)\end{array}$ & $\begin{array}{l}174.67 \\
(38.89)\end{array}$ & $\begin{array}{l}174.81 \\
(32.34)\end{array}$ & $\begin{array}{l}163.50 \\
(38.52)\end{array}$ \\
\hline
\end{tabular}


American Research Journal of Bio Sciences(ARJB)

\begin{tabular}{|c|c|c|c|c|c|c|c|c|c|c|c|}
\hline \multirow{4}{*}{ 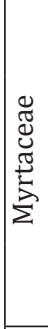 } & \multirow[t]{2}{*}{ Eucalyptus grandis } & $\mathrm{NaOH}$ & $\begin{array}{c}211.6 \\
(18.39)\end{array}$ & $\begin{array}{l}216.00 \\
(16.29)\end{array}$ & $\begin{array}{l}200.40 \\
(20.95)\end{array}$ & $\begin{array}{l}210.30 \\
(16.62)\end{array}$ & $\begin{array}{l}210.80 \\
(17.22)\end{array}$ & $\begin{array}{l}180.60 \\
(23.39)\end{array}$ & $\begin{array}{l}219.60 \\
(21.90)\end{array}$ & $\begin{array}{l}214.90 \\
(22.10)\end{array}$ & $\begin{array}{l}171.96 \\
(35.95)\end{array}$ \\
\hline & & $\mathrm{FeCl}_{3}$ & $\begin{array}{l}181.00 \\
(15.38)\end{array}$ & $\begin{array}{l}185.71 \\
(13.68)\end{array}$ & $\begin{array}{l}189.75 \\
(25.11)\end{array}$ & $\begin{array}{l}184.37 \\
(16.65)\end{array}$ & $\begin{array}{l}189.83 \\
(19.30)\end{array}$ & $\begin{array}{l}186.79 \\
(24.19)\end{array}$ & $\begin{array}{l}181.32 \\
(20.20)\end{array}$ & $\begin{array}{l}186.13 \\
(23.91)\end{array}$ & $\begin{array}{l}186.13 \\
(33.09)\end{array}$ \\
\hline & \multirow[t]{2}{*}{ Eugenia uniflora } & $\mathrm{NaOH}$ & $\begin{array}{l}166.62 \\
(13.05)\end{array}$ & $\begin{array}{l}191.43 \\
(13.24)\end{array}$ & $\begin{array}{l}179.57 \\
(17.50)\end{array}$ & $\begin{array}{l}162.89 \\
(12.38)\end{array}$ & $\begin{array}{l}183.40 \\
(13.46)\end{array}$ & $\begin{array}{c}152.24 \\
(13.845\end{array}$ & $\begin{array}{l}154.66 \\
(38.67)\end{array}$ & $\begin{array}{l}177.89 \\
(34.72)\end{array}$ & $\begin{array}{l}139.29 \\
(26.98)\end{array}$ \\
\hline & & $\mathrm{FeCl}_{3}$ & $\begin{array}{l}151.08 \\
(25.43)\end{array}$ & $\begin{array}{l}145.18 \\
(24.03)\end{array}$ & $\begin{array}{l}135.15 \\
(32.24)\end{array}$ & $\begin{array}{l}141.10 \\
(27.44)\end{array}$ & $\begin{array}{l}140.05 \\
(25.30)\end{array}$ & $\begin{array}{l}127.18 \\
(29.00)\end{array}$ & $\begin{array}{l}138.06 \\
(31.43)\end{array}$ & $\begin{array}{l}125.23 \\
(30.59)\end{array}$ & $\begin{array}{l}110.69 \\
(33.74)\end{array}$ \\
\hline \multirow{6}{*}{ 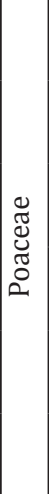 } & \multirow[t]{3}{*}{$\begin{array}{l}\text { Andropogan } \\
\text { bicornis }\end{array}$} & $\mathrm{NaOH}$ & $\begin{array}{l}153.72 \\
(25.59)\end{array}$ & $\begin{array}{l}163.85 \\
(21.91)\end{array}$ & $\begin{array}{l}167.10 \\
(25.34)\end{array}$ & $\begin{array}{l}161.45 \\
(35.42)\end{array}$ & $\begin{array}{l}169.48 \\
(26.67)\end{array}$ & $\begin{array}{l}169.10 \\
(32.07)\end{array}$ & $\begin{array}{l}149.84 \\
(36.67)\end{array}$ & $\begin{array}{l}160.10 \\
(37.87)\end{array}$ & $\begin{array}{l}169.10 \\
(32.07)\end{array}$ \\
\hline & & $\mathrm{FeCl}_{3}$ & $\begin{array}{l}144.27 \\
(40.68)\end{array}$ & $\begin{array}{l}140.78 \\
(41.18)\end{array}$ & $\begin{array}{l}120.30 \\
(4379)\end{array}$ & $\begin{array}{l}153.92 \\
(47.49)\end{array}$ & $\begin{array}{l}147.49 \\
(40.69)\end{array}$ & $\begin{array}{l}129.59 \\
(40.23)\end{array}$ & $\begin{array}{l}137.02 \\
(54.57)\end{array}$ & $\begin{array}{l}129.36 \\
(43.44)\end{array}$ & $\begin{array}{l}129.59 \\
(40.23)\end{array}$ \\
\hline & & $\begin{array}{l}\mathrm{NaOH}+ \\
\text { Safranin }\end{array}$ & $\begin{array}{l}181.95 \\
(35.26)\end{array}$ & $\begin{array}{l}181.23 \\
(33.50)\end{array}$ & $\begin{array}{l}188.95 \\
(35.37)\end{array}$ & $\begin{array}{l}170.69 \\
(39.11)\end{array}$ & $\begin{array}{l}161.79 \\
(33.44)\end{array}$ & $\begin{array}{l}169.18 \\
(35.86)\end{array}$ & $\begin{array}{l}179.79 \\
(35.88)\end{array}$ & $\begin{array}{l}157.04 \\
(26.72)\end{array}$ & $\begin{array}{l}169.18 \\
(35.86)\end{array}$ \\
\hline & \multirow[t]{3}{*}{$\begin{array}{c}\text { Erianthus } \\
\text { angustifolius }\end{array}$} & $\mathrm{NaOH}$ & $\begin{array}{l}163.77 \\
(19.04)\end{array}$ & $\begin{array}{l}167.85 \\
(21.82)\end{array}$ & $\begin{array}{l}172.12 \\
(24.93)\end{array}$ & $\begin{array}{l}165.85 \\
(28.09)\end{array}$ & $\begin{array}{l}168.66 \\
(24.03)\end{array}$ & $\begin{array}{l}164.72 \\
(28.60)\end{array}$ & $\begin{array}{l}158.57 \\
(32.41)\end{array}$ & $\begin{array}{l}164.52 \\
(31.86)\end{array}$ & $\begin{array}{l}161.14 \\
(33.33)\end{array}$ \\
\hline & & $\mathrm{FeCl}_{3}$ & $\begin{array}{l}153.73 \\
(21.78)\end{array}$ & $\begin{array}{l}150.00 \\
(18.95)\end{array}$ & $\begin{array}{l}138.50 \\
(24.26)\end{array}$ & $\begin{array}{l}146.46 \\
(50.08)\end{array}$ & $\begin{array}{l}141.84 \\
(36.52)\end{array}$ & $\begin{array}{l}129.79 \\
(37.53)\end{array}$ & $\begin{array}{l}95.744 \\
(46.89)\end{array}$ & $\begin{array}{l}112.06 \\
(34.32)\end{array}$ & $\begin{array}{l}112.42 \\
(35.93)\end{array}$ \\
\hline & & $\begin{array}{c}\mathrm{NaOH}+ \\
\text { Safranin }\end{array}$ & $\begin{array}{l}144.37 \\
(20.68)\end{array}$ & $\begin{array}{l}132.30 \\
(21.78)\end{array}$ & $\begin{array}{l}142.07 \\
(21.75)\end{array}$ & $\begin{array}{l}147.22 \\
(34.92)\end{array}$ & $\begin{array}{l}130.88 \\
(30.88)\end{array}$ & $\begin{array}{l}143.74 \\
(29.60)\end{array}$ & $\begin{array}{l}103.07 \\
(56.25)\end{array}$ & $\begin{array}{l}80.644 \\
(39.30)\end{array}$ & $\begin{array}{l}89.356 \\
(39.89)\end{array}$ \\
\hline \multirow{4}{*}{ 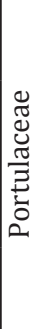 } & \multirow[t]{2}{*}{ Portulaca striata } & $\mathrm{NaOH}$ & $\begin{array}{l}172.10 \\
(34.07)\end{array}$ & $\begin{array}{l}159.23 \\
(28.54)\end{array}$ & $\begin{array}{l}110.47 \\
(38.70)\end{array}$ & $\begin{array}{l}171.29 \\
(34.07)\end{array}$ & $\begin{array}{l}152.16 \\
(28.75)\end{array}$ & $\begin{array}{l}95.167 \\
(35.05)\end{array}$ & $\begin{array}{l}151.30 \\
(72.72)\end{array}$ & $\begin{array}{l}133.04 \\
(57.87)\end{array}$ & $\begin{array}{l}55.644 \\
(49.12)\end{array}$ \\
\hline & & $\mathrm{FeCl}_{3}$ & $\begin{array}{l}163.82 \\
(27.90)\end{array}$ & $\begin{array}{l}170.25 \\
(25.34)\end{array}$ & $\begin{array}{l}190.12 \\
(33.01)\end{array}$ & $\begin{array}{l}167.95 \\
(29.70)\end{array}$ & $\begin{array}{l}178.74 \\
(27.17)\end{array}$ & $\begin{array}{l}190.57 \\
(36.07)\end{array}$ & $\begin{array}{l}132.23 \\
(37.09)\end{array}$ & $\begin{array}{l}151.78 \\
(33.43)\end{array}$ & $\begin{array}{l}169.39 \\
(39.71)\end{array}$ \\
\hline & \multirow[t]{2}{*}{$\begin{array}{l}\text { Talinum } \\
\text { triangulare }\end{array}$} & $\mathrm{NaOH}$ & $\begin{array}{l}169.28 \\
(28.22)\end{array}$ & $\begin{array}{l}151.10 \\
(29.61)\end{array}$ & $\begin{array}{l}131.82 \\
(35.82)\end{array}$ & $\begin{array}{l}186.16 \\
(35.13)\end{array}$ & $\begin{array}{l}159.92 \\
(33.46)\end{array}$ & $\begin{array}{l}124.25 \\
(38.95)\end{array}$ & $\begin{array}{l}125.03 \\
(75.06)\end{array}$ & $\begin{array}{l}108.21 \\
(60.43)\end{array}$ & $\begin{array}{l}66.267 \\
(58.76)\end{array}$ \\
\hline & & $\mathrm{FeCl}_{3}$ & $\begin{array}{l}163.53 \\
(32.98)\end{array}$ & $\begin{array}{l}175.58 \\
(25.88)\end{array}$ & $\begin{array}{l}175.55 \\
(40.55)\end{array}$ & $\begin{array}{l}164.26 \\
(35.05)\end{array}$ & $\begin{array}{l}167.78 \\
(32.76)\end{array}$ & $\begin{array}{l}150.59 \\
(50.47)\end{array}$ & $\begin{array}{l}151.56 \\
(46.19)\end{array}$ & $\begin{array}{l}154.82 \\
(43.84)\end{array}$ & $\begin{array}{l}136.99 \\
(53.54)\end{array}$ \\
\hline \multirow{4}{*}{ 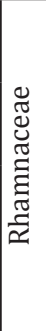 } & \multirow[t]{2}{*}{ Hovenia dulcis } & $\mathrm{NaOH}$ & $\begin{array}{l}111.68 \\
(15.93)\end{array}$ & $\begin{array}{l}116.58 \\
(15.37)\end{array}$ & $\begin{array}{l}95.983 \\
(13.08)\end{array}$ & $\begin{array}{l}116.32 \\
(16.05)\end{array}$ & $\begin{array}{l}122.47 \\
(14.26)\end{array}$ & $\begin{array}{c}103.32 \\
(15.35)\end{array}$ & $\begin{array}{l}113.29 \\
(17.92)\end{array}$ & $\begin{array}{l}112.66 \\
(16.55)\end{array}$ & $\begin{array}{l}85.400 \\
(13.35)\end{array}$ \\
\hline & & $\mathrm{FeCl}_{3}$ & $\begin{array}{l}162.08 \\
(33.91)\end{array}$ & $\begin{array}{l}161.07 \\
(29.56)\end{array}$ & $\begin{array}{l}153.72 \\
(28.12)\end{array}$ & $\begin{array}{l}158.06 \\
(35.27)\end{array}$ & $\begin{array}{l}158.85 \\
(31.18)\end{array}$ & $\begin{array}{l}151.82 \\
(32.73)\end{array}$ & $\begin{array}{l}135.77 \\
(48.67)\end{array}$ & $\begin{array}{l}140.70 \\
(39.45)\end{array}$ & $\begin{array}{l}136.83 \\
(41.38)\end{array}$ \\
\hline & \multirow[t]{2}{*}{ Scutia buxifolia } & $\mathrm{NaOH}$ & $\begin{array}{l}158.60 \\
(31.26)\end{array}$ & $\begin{array}{l}155.72 \\
(25.36)\end{array}$ & $\begin{array}{l}35.950 \\
(39.79)\end{array}$ & $\begin{array}{l}161.57 \\
(33.49) \\
\end{array}$ & $\begin{array}{l}165.35 \\
(33.68) \\
\end{array}$ & $\begin{array}{l}88.150 \\
(28.94)\end{array}$ & $\begin{array}{l}164.73 \\
(42.09) \\
\end{array}$ & $\begin{array}{l}164.73 \\
(42.09) \\
\end{array}$ & $\begin{array}{l}92.922 \\
(32.34) \\
\end{array}$ \\
\hline & & $\mathrm{FeCl}_{3}$ & $\begin{array}{l}156.37 \\
(34.05)\end{array}$ & $\begin{array}{l}150.40 \\
(30.27)\end{array}$ & $\begin{array}{l}131.50 \\
(39.76)\end{array}$ & $\begin{array}{l}168.33 \\
(31.21)\end{array}$ & $\begin{array}{l}163.61 \\
(27.38)\end{array}$ & $\begin{array}{l}151.89 \\
(34.48)\end{array}$ & $\begin{array}{l}137.20 \\
(39.11)\end{array}$ & $\begin{array}{l}137.20 \\
(39.11)\end{array}$ & $\begin{array}{l}123.23 \\
(47.62)\end{array}$ \\
\hline \multirow{4}{*}{ 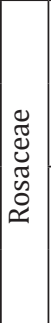 } & \multirow[t]{2}{*}{ Fragaria vesca } & $\mathrm{NaOH}$ & $\begin{array}{l}197.00 \\
(31.66)\end{array}$ & $\begin{array}{l}182.25 \\
(29.31)\end{array}$ & $\begin{array}{l}170.32 \\
(34.01)\end{array}$ & $\begin{array}{l}189.61 \\
(40.44)\end{array}$ & $\begin{array}{l}177.16 \\
(33.37)\end{array}$ & $\begin{array}{l}151.89 \\
(42.10)\end{array}$ & $\begin{array}{l}176.90 \\
(47.96)\end{array}$ & $\begin{array}{l}156.28 \\
(53.26)\end{array}$ & $\begin{array}{l}136.31 \\
(53.75)\end{array}$ \\
\hline & & $\mathrm{FeCl}_{3}$ & $\begin{array}{l}158.38 \\
(37.57)\end{array}$ & $\begin{array}{l}143.03 \\
(29.52)\end{array}$ & $\begin{array}{l}128.67 \\
(29.02)\end{array}$ & $\begin{array}{l}163.16 \\
(30.70)\end{array}$ & $\begin{array}{l}143.72 \\
(25.68)\end{array}$ & $\begin{array}{l}107.79 \\
(26.05)\end{array}$ & $\begin{array}{l}146.10 \\
(36.32)\end{array}$ & $\begin{array}{l}133.04 \\
(25.72)\end{array}$ & $\begin{array}{l}100.06 \\
(25.87) \\
\end{array}$ \\
\hline & \multirow[t]{2}{*}{ Rubus occidentalis } & $\mathrm{NaOH}$ & $\begin{array}{l}120.02 \\
(20.21)\end{array}$ & $\begin{array}{l}127.70 \\
(23.32)\end{array}$ & $\begin{array}{l}113.30 \\
(23.80)\end{array}$ & $\begin{array}{l}121.62 \\
(24.69)\end{array}$ & $\begin{array}{l}123.82 \\
(23.96)\end{array}$ & $\begin{array}{c}103.32 \\
(22.05)\end{array}$ & $\begin{array}{l}105.84 \\
(21.68)\end{array}$ & $\begin{array}{l}117.88 \\
(21.88)\end{array}$ & $\begin{array}{l}106.14 \\
(23.77)\end{array}$ \\
\hline & & $\mathrm{FeCl}_{3}$ & $\begin{array}{l}111.67 \\
(26.79)\end{array}$ & $\begin{array}{l}117.55 \\
(24.65)\end{array}$ & $\begin{array}{l}118.33 \\
(34.67)\end{array}$ & $\begin{array}{l}141.68 \\
(31.75)\end{array}$ & $\begin{array}{l}143.49 \\
(26.45)\end{array}$ & $\begin{array}{l}133.89 \\
(24.91)\end{array}$ & $\begin{array}{l}137.60 \\
(31.95)\end{array}$ & $\begin{array}{l}134.60 \\
(29.00)\end{array}$ & $\begin{array}{l}133.14 \\
(34.19)\end{array}$ \\
\hline
\end{tabular}


Fig1. Light microscopic images captured with 400x magnification. (A) Baccharis dracunculifolia stained using the sodium hydroxide method. (B) Baccharis dracunculifolia stained using the iron chloride method. (C) Euphorbia millii stained using the sodium hydroxide method. (D) Euphorbia millii stained using the iron chloride method. (E) Baccharis trimera stained using the sodium hydroxide method. (F) Baccharis trimera stained using the iron chloride method. (G) Ricinus communis stained using the sodium hydroxide method. (H) Ricinus communis stained using the iron chloride method. (I) Eucalyptus grandis stained using the sodium hydroxide method. (J) Eucalyptus grandis stained using the iron chloride method. (K) Portulaca striata stained using the sodium hydroxide method. (L) Portulaca striata stained using the iron chloride method. (M) Eugenia uniflora stained using the sodium hydroxide method. (N) Eugenia uniflora stained using the iron chloride method. (O) Talinum triangulare stained using the sodium hydroxide method. (P) Talinum triangulare stained using the iron chloride method. Scale bar: 10 $\mu m$
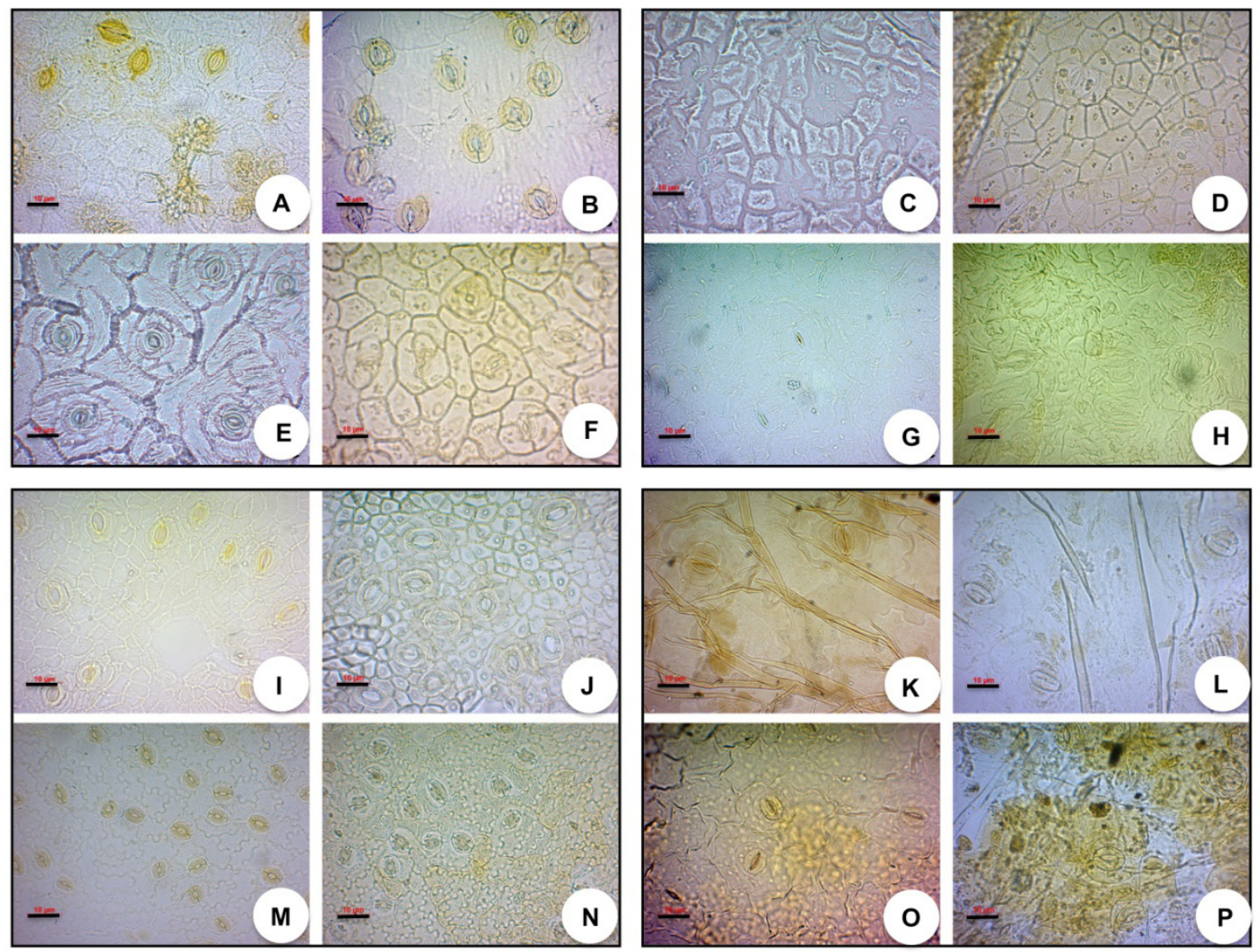
Fig2. Light microscopic images captured with 400x magnification. (A) Malvastrum coromandelianum stained using the sodium hydroxide method. (B) Malvastrum coromandelianum stained using the iron chloride method. (C) Hyptis arvensis stained using the sodium hydroxide method. (D) Hyptis arvensis stained using the iron chloride method. (E) Triumfetta semitriloba stained using the sodium hydroxide method. (F) Triumfetta semitriloba stained using the iron chloride method. $(G)$ Ocimum basillicum stained using the sodium hydroxide method. (H) Ocimum basillicum stained using the iron chloride method. (I) Hovenia dulcis stained using the sodium hydroxide method. (J) Hovenia dulcis stained using the iron chloride method. (K) Fragaria vesca stained using the sodium hydroxide method. (L) Fragaria vesca stained using the iron chloride method. (M) Scutia buxifolia stained using the sodium hydroxide method. (N) Scutia buxifolia stained using the iron chloride method. (O) Rubus occidentalis stained using the sodium hydroxide method. (P) Rubus occidentalis stained using the iron chloride method. Scale bar: 10 $\mu \mathrm{m}$
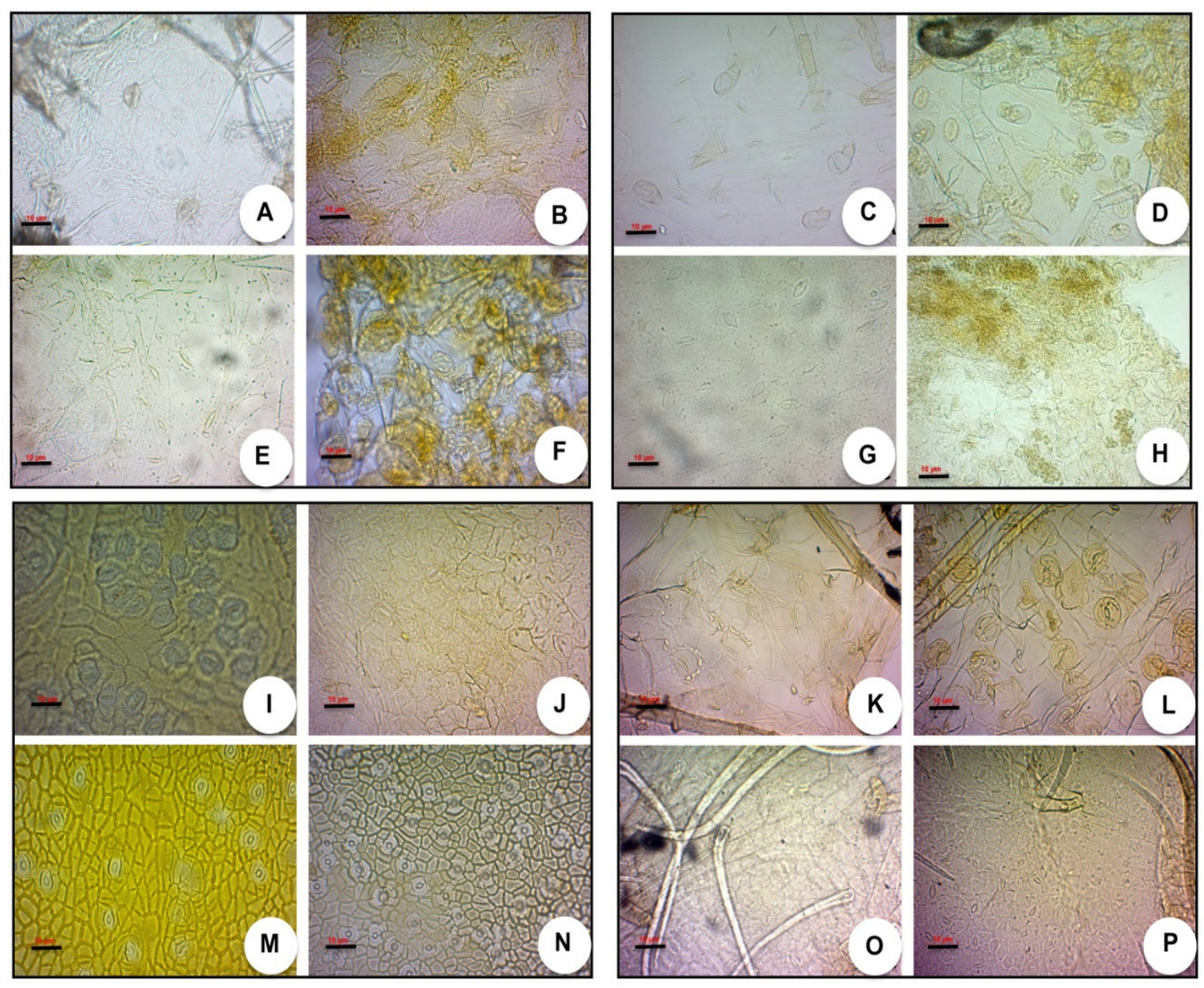
Fig3. Light microscopic images captured with 400x magnification. (A) Andropogom bicornisi stained using the sodium hydroxide method. (B) Andropogom bicornisi stained using sodium hydroxide plus safranin. (C) Andropogom bicornis stained using the iron chloride method. (D) Erianthus angustifolius stained using the sodium hydroxide method. (E) Erianthus angustifolius stained using sodium hydroxide plus safranin. (F) Erianthus angustifolius stained using the iron chloride method. $(G)$ Cyperus distans stained using the sodium hydroxide method. $(H)$ Cyperus distans stained using sodium hydroxide plus safranin. (I) Cyperus distans stained using the iron chloride method. (J) Cyperus rotundus stained using the sodium hydroxide method. (K) Cyperus rotundus stained using sodium hydroxide plus safranin. (L) Cyperus rotundus stained using the iron chloride method. Scale bar: $10 \mu \mathrm{m}$

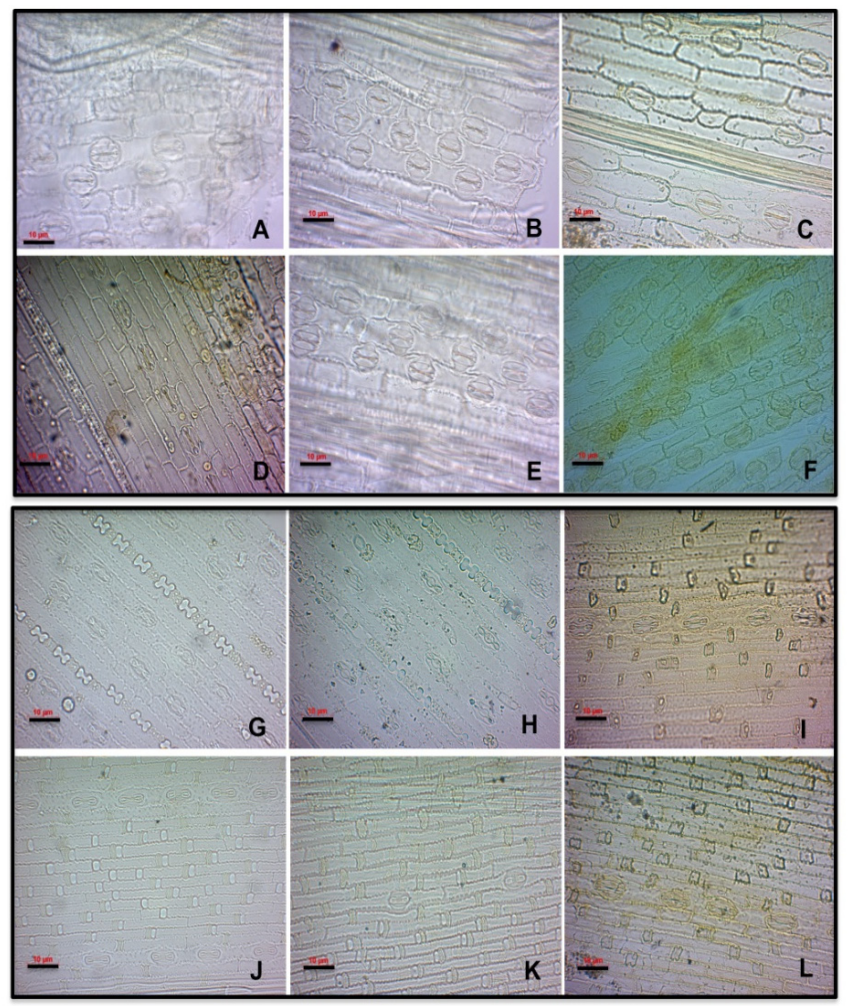

Fig4. Light micrograph pictures of Eugenia uniflora captured with 1000x magnification. (A) staining with the sodium hydroxide method; (B) staining with the iron chloride method. Scale bar: $10 \mu \mathrm{m}$

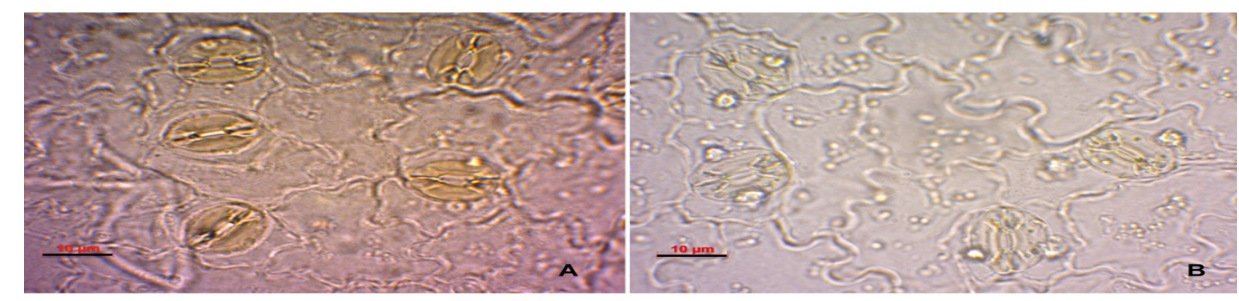




\section{ACKNOWLEDGEMENTS}

Authors acknowledge the financial support, grants and scholarships provided by CNPq/Brazil (Process 474758/2012-5 and 442995/2014-8), CAPES, FAPERGS and Universidade Federal do Pampa (PROPESQ and PROPG).

\section{REFERENCES}

[1] Conde E, Cadahía E, García-Vallejo MC. (1997). High-pressure liquid chromatographic analysis of polyphenols in leaves of Eucalyptus camaldulensis, globulus and rudis: Proanthocyanidins, ellagitannins and flavonol glycosides. Phytochemical Analysis. 8(2): 78-83.

[2] Costa AF, Cunha AP (2000). Farmacognosia v. 3. Lisboa: Editora Calouste Gulbenkian.

[3] Dai J, Mumper RJ (2010). Plant phenolics: extraction, analysis and their antoixidant and anticancer properties. Molecules 15: 7313-7352.

[4] Heath MC (2002). Secondary metabolites and plant defence. Physiol Mol Plant Pathol 60: 273-274.

[5] Horobin RW (2001). Histochemical staining. Editora John Wiley \& Sons : 172p.

[6] Johansen DA (1940). Plant microtechnique. New York, McGraw-Hill Book Co. Inc., 523 p.

[7] Laloraya MM, Nozzolillo C, Purohit S, Stevenson L (1986). Reversal of Absicisic Acid induced stomatal closure by trans-cinnamic and p-coumaric acid. Plant Physiol 81, 253-258.

[8] Lattanzio V, Lattanzio VMT, Cardinali A (2006). Role of phenolics in the resistande mechanisms of plants angainst fungal pathogens and insects. In: Imperato F. (ed.) Phytochemistry: Advances in research. Reaserch Signpost, Kerala. p. 23-67.

[9] Matem U, Kneusel R (1988). Phenolic compounds in plants disease resistance. Phytoparasitica 16: 153-170.

[10] Medeiros RB, Ferreira MASV, Dianese JC (2003). Mecanismos de agressão e defesa nas Interações plantapatógeno. p. 289.

[11] Nicholson RL, Hammerschindt R (1992). Phenolic compounds and their role in disease resistance. Annu Rev Phytopathol 30: 369-389.

[12] Teixeira MP, Cruz L, Franco JL, Vieira RB, Stefenon VM (2016). Ethnobotany and antioxidant evaluation of commercialized medicinal plants from the Brazilian Pampa. Acta Bot Bras 30: 47-59.

[13] White BL, Howard LR, Prior RL (2010). Release of Bound Procyanidins from Cranberry Pomace by Alkaline Hydrolysis. J Agric Food Chem 58: 7572-7579.

Citation: Valdir Marcos Stefenon, Nucleus of Plant Tissue Culture, Universidade Federal do Pampa, BR290 km 423, Bairro Pirai, 97300-000, São Gabriel, RS, Brazil. A new approach for light microscopy studies of stomatal complex using sodium hydroxide staining American Research Journal of Biosciences Volume 2016; pp:1-10

Copyright (c) 2016 Valdir Marcos Stefenon This is an open access article distributed under the Creative Commons Attribution License, which permits unrestricted use, distribution, and reproduction in any medium, provided the original work is properly cited. 